\title{
Neophobia and social facilitation in narrow-striped mongooses
}

\author{
Bako N. Rasolofoniaina ${ }^{1}$ (D) Peter M. Kappeler ${ }^{1,2} \cdot$ Claudia Fichtel $^{2}$
}

Received: 17 November 2019 / Revised: 6 September 2020 / Accepted: 11 September 2020 / Published online: 21 September 2020 (c) The Author(s) 2020

\begin{abstract}
Social learning is widespread in the animal kingdom, but individuals can differ in how they acquire and use social information. Personality traits, such as neophobia, may, for example, promote individual learning strategies. Here, we contribute comparative data on social learning strategies in carnivorans by examining whether narrow-striped mongooses (Mungotictis decemlineata), a group-living Malagasy euplerid, learn socially and whether neophobia influences social learning. To this end, we tested seven wild female groups with a two-option artificial feeding box, using a demonstrator-observer paradigm, and conducted novel object tests to assess neophobia. In five groups, one individual was trained as a demonstrator displaying one of the techniques, whereas the other two groups served as control groups. Neophobia did not co-vary with an individual's propensity to seek social information. However, less neophobic individuals, and individuals that tended to seek social information, learned the task faster. Moreover, individuals in demonstrator groups learned the task faster than those in groups without a demonstrator and used the demonstrated technique more often. Hence, narrow-striped mongooses rely on social facilitation and local or stimulus enhancement to solve new problems. Finally, our results suggest that several individual characteristics should be taken into consideration to obtain a more comprehensive understanding of social learning strategies.
\end{abstract}

Keywords Carnivora $\cdot$ Social facilitation $\cdot$ Neophobia $\cdot$ Attendance bias $\cdot$ Mungotictis decemlineata

\section{Introduction}

Learning by observing others is a mechanism for behavioural plasticity that can shape the behavioural repertoire of an individual (Kendal et al. 2010; Aplin 2016). Social learning is associated with many benefits, from acquiring behavioural traits in different contexts to the establishment of cultural behaviour across populations (Aplin 2016; Whiten and van de Waal 2018). However, social learning also comes with costs, as it can spread incorrect information (Rieucau and Giraldeau 2011). Consequently, individuals should ideally switch flexibly between asocial and social learning strategies (Kendal et al. 2018). To maximize the benefits, an individual should flexibly use social learning strategies to decide from

Bako N. Rasolofoniaina

BRasolofoniaina@dpz.eu

1 Dept. Sociobiology/Anthropology, Johann-Friedrich-Blumenbach Institute of Zoology and Anthropology, University Göttingen, Göttingen, Germany

2 Behavioral Ecology and Sociobiology Unit, German Primate Center Leibniz Institute for Primate Research, Göttingen, Germany whom and when to learn, and which information to acquire (Laland 2004; Kendal et al. 2018). Social learning strategies encompass social information seeking and its use or application in future contexts. For instance, one type of a social learning strategy, the "state-based strategy", depends on the observer's intrinsic characteristics, such as rank, age, and sex, which may influence its decision to learn socially in a given situation (Kendal et al. 2018). Moreover, a statebased strategy will influence an individual's choice to be attentive to a conspecific to seek social information, triggering a preferential attendance bias (Kendal et al. 2018), resulting in directed social learning or a transmission bias (Kendal et al. 2015). As a result, the tendency to seek and use social information can vary at the individual level across group members (Mesoudi et al. 2016; Watson et al. 2018).

One of the main factors driving this variation is animal personality, i.e., individual differences in behaviour that are consistent across time and contexts (Réale et al. 2007; Kurvers et al. 2010a; Mesoudi et al. 2016). Personality traits, such as boldness, neophobia or exploration, appear to influence the tendency to use social information and provide a benefit against danger in a high-risk environment (Greggor et al. 2015; Crane and Ferrari 2017). For example, in a 
social foraging experiment, shyer barnacle geese (Branta leucopsis) were more likely to use social information than their bolder conspecifics because they had fewer opportunities to gather individual information and, hence, relied more on conspecific demonstrators to find high-quality food patches (Kurvers et al. 2010a). In contrast, in great tits (Parus major), bolder individuals were more inclined to profit from social learning because the more fearless individuals hindered shyer individuals from participating in the learning situation (Marchetti and Drent 2000). Furthermore, neophobia can also be transmitted socially as for example in fathead minnows (Pimephales promelas), where naïve observers also learned neophobic responses from a demonstrator in a social learning paradigm (Crane et al. 2015).

Exploration influenced social learning in a study examining mate choice and food choice, with less explorative female zebra finches (Taeniopygia guttata) copying the decision exhibited by a conspecific model even if it would lead to unfavourable choices, such as the choice of a non-preferred male or non-preferred food (Rosa et al. 2012). Although female zebra finches were previously tested for their individual preferences, they still followed the model's choice, indicating that they prioritised social information over personal information (Rosa et al. 2012). In three-spined sticklebacks (Gasterosteus aculeatus), more explorative individuals were more likely to join an unfamiliar demonstrator because less explorative individuals needed more time to familiarize themselves with the new conspecific and were, hence, more sensitive to risk (Nomakuchi et al. 2009). Therefore, personality traits can modify the tendency to learn socially by obtaining access to either personal or social information, as well as the tendency to rely more on social learning in contexts where unfamiliar objects/conspecifics are involved. However, whereas the effect of exploratory behaviours on social learning is well known (summarised in Mesoudi et al. 2016), the effect of neophobia on the tendency to seek social information remains obscure in comparison.

Although social learning is widespread across animals (insects: Slaa et al. 2003; Grüter and Leadbeater 2014; fish: Nomakuchi et al. 2009; Webster and Laland 2017; birds: Marchetti and Drent 2000; Morales Picard et al. 2017; carnivorans: Thornton and Clutton-Brock 2011; primates: Schnoell and Fichtel 2012; van de Waal et al. 2013), it has been less often studied experimentally in social carnivores. For instance, spotted hyenas (Crocuta crocuta) did not learn socially in a problem-solving task (Benson-Amram et al. 2014). For meerkats (Suricata suricatta), however, individuals preferentially chose the landmark in a two-choice task that was also preferred by a demonstrator, indicating inadvertent social learning via stimulus enhancement (Thornton and Malapert 2009). Teaching, a highly derived form of social learning, has been shown in meerkats, with adults providing pups opportunities to interact with live prey to learn prey-handling skills (Thornton and McAuliffe 2006). Moreover, young banded mongooses (Mungos mungo) imitate the foraging technique exhibited by adult individuals (Müller and Cant 2010). Thus, patterns of social learning appear to be highly variable across carnivorans.

To contribute new comparative data to this field of research, we investigated the presence of social learning in narrowstriped mongooses (Mungotictis decemlineata). Specifically, we examined the influence of personality on an individual's probability to learn socially in a social diffusion task. Female narrow-striped mongooses live in stable, hierarchical groups (3.7 \pm 0.4 individuals) (Schneider and Kappeler 2016), and exhibit a generalist and opportunistic feeding ecology (Rasolofoniaina et al. 2019). Group members regularly forage for hidden prey, which may present opportunities for social learning to acquire relevant hunting strategies, exploration of novel food, or space use. In particular, we examined whether an individual's tendency to learn socially is related to individual variation in neophobia, because neophobia is generally thought to hinder individual learning (Webster and Lefebvre 2001).

Using field experiments, we examined individual variation in neophobia by presenting novel objects, and we studied social learning by conducting a social diffusion experiment. Social diffusion experiments are set out to study how founder behaviours spread across multiple individuals in a group (Whiten and Mesoudi 2008). By presenting an artificial feeding apparatus that can be opened by two different techniques and for which demonstrators have been trained to use only one of the two techniques, social learning has been demonstrated in various species (primates: Pesendorfer et al. 2009; van de Waal et al. 2010; Schnoell and Fichtel 2012; Claidière et al. 2013; birds: Morales Picard et al. 2017). To investigate experimentally social learning, we confronted narrow-striped mongooses with such a two-option feeding apparatus. We predicted that: (1) if neophobia positively influences the propensity to observe the demonstrator, more neophobic individuals are expected to spend more time with the demonstrator manipulating the task than less neophobic individuals, (2) If neophobia positively influences social learning, less neophobic individuals are expected to learn the task faster than more neophobic individuals, (3) If narrow-striped mongooses learn socially, we predicted that the presence of a demonstrator should improve the learning speed of observers compared to individuals learning without demonstrator, and (4) individuals are more likely to use the demonstrated technique to open the feeding appartus.

\section{Methods}

\section{Study animals and general testing procedure}

Between November 2014 and September 2017, we studied seven female groups (Table 1) from an individually-marked 
Table 1 Group composition (all female adults and the juveniles and infants of unknown sex) and experimental condition during the social learning task

\begin{tabular}{lll}
\hline Group & Number of individuals & Condition \\
\hline B & 3 (3 adults) & Control \\
L & 3 ( 2 adults and 1 juvenile $)$ & Control \\
C & 6 (4 adults and 2 juveniles $)$ & Pull \\
N & $4(2$ adults, 1 juvenile and 1 infant $)$ & Pull \\
G1 & 2 (1 adult and 1 infant $)$ & Pull \\
L1 & 2 (2 adults $)$ & Slide \\
M & 5 (5 adults $)$ & Slide \\
\hline
\end{tabular}

population of free-ranging narrow-striped mongooses (Schneider and Kappeler 2016) in Kirindy Forest, Madagascar. Individuals in a group were marked either by radio-collars or with specific fur-shaving patterns on the tail. Groups were located within their territory using radio-tracking and were tested opportunistically. For testing, we used the following general experimental procedure: apparatuses were baited with dry cat food out of sight of the individuals, and animals were lured with an acoustic signal, shaking a plastic box containing cat food to the experimental area (Schnoell and Fichtel 2012). The experiment started when the first individual of the group approached one of the apparatuses within a range of $3 \mathrm{~m}$ and ended when the last individual left the arena.

\section{Novel object test}

Neophobia was assessed by presenting a novel object next to a wooden plate containing food. Both objects were placed in the middle of a metal ring, allowing an accurate estimate of the distance between the subject and the novel object. Individuals were previously habituated to the metal ring before conducting the novel object test. To avoid monopolisation by certain individuals, we presented one experimental set-up per individual. To assess the repeatability of the personality trait "neophobia," we conducted two novel object tests, by presenting either colourful plastic balls or red plastic cups as novel objects. In six groups, we repeated the novel object test after a period of 3 years, whereas in one group, marked at the end of the study, we repeated the novel object test after a period of 4 months. The average time between the two novel object tests was $12.5 \pm 12.02$ (mean $\pm \mathrm{SD}$ ) months. We tested 33 individuals in the first novel object test but only 15 individuals in the second novel object test, due to individual losses over the 3 years or a lack of motivation of some individuals to approach the experimental area.

Based on video-recordings, we measured the following behaviours from the two novel object tests: latency to enter the metal ring, latency to contact the novel object, and latency to feed next to the novel object. We estimated the repeatability of each individual latency with individuals that participated in both novel object tests $(N=15)$, using the package "rptR" (Nakagawa and Schielzeth 2010). Before the analyses, we log-transformed the variables to achieve normality. We computed point estimates of repeatability $R, p$ values, standard errors SE, and the confidence intervals with bootstrapping. The significant repeatable latency to feed next to the novel object was retained and defined as "neophobia." Individuals exhibiting longer latencies were categorised as more neophobic, whereas those with shorter latencies were the less neophobic ones.

\section{Social learning experimental set-up}

A problem-solving feeding apparatus (Fig. 1) was constructed similar to an apparatus that has been used in a study of social learning in vervet monkeys (Chlorocebus aethiops) (van de Waal and Bshary 2011). The apparatus consisted of a wooden box $(9.5 \mathrm{~cm} \times 13.6 \mathrm{~cm})$, with a transparent plexiglass door, fixed on a wooden plate $(13 \mathrm{~cm} \times 17 \mathrm{~cm})$. The door could be opened via two opening mechanisms, by either pulling or sliding the plexiglass door. We first trained a demonstrator by presenting only one box that could be opened by one technique only. Following this training, we conducted the group experiment by presenting several boxes that could be opened by both techniques and we presented one box for each group member. In total, we tested seven groups: five groups in which a demonstrator was trained to open the box with either the pull ( $N=3$ groups) or the slide technique ( $N=2$ groups), and two groups in which no demonstrator was trained served as control groups. For the control groups $(N=2)$, we used boxes that could be opened by both techniques.

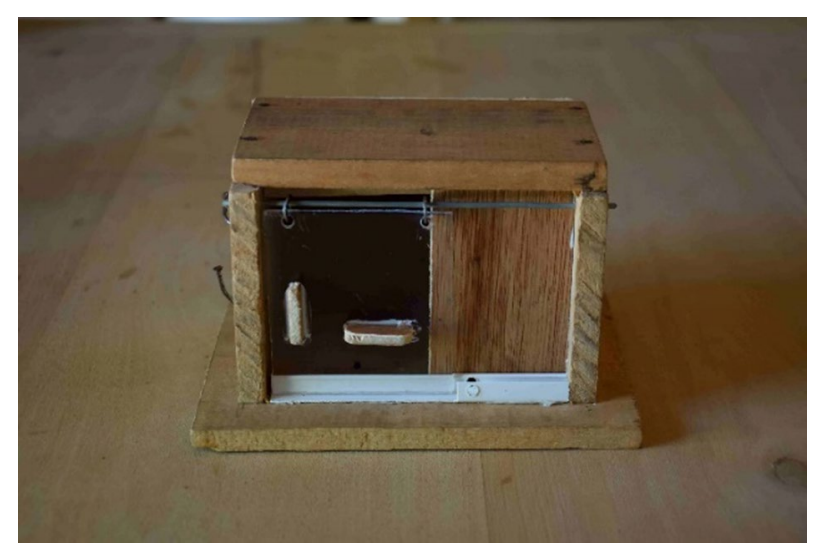

Fig. 1 Two-option foraging apparatus used to assess social learning. The door can be opened by either sliding or pulling 


\section{Demonstrator training procedure}

To train the demonstrator, only one feeding apparatus was presented, which was monopolized across sessions and groups by the oldest and dominant female of a group, and she served as the demonstrator (Schneider and Kappeler 2016). In three groups, we trained the demonstrator to open the apparatus with the pull technique by blocking the slide technique, whereas in the other two groups, we trained the demonstrator to open the apparatus with the slide technique. For the training, we presented the boxes once per day and the demonstrator could perform only one trial over the course of 20 days, resulting in 20 trials performed by the demonstrator. To ensure that they had learned the task, each demonstrator had to open the box more often than expected by chance by reaching a learning criterion of $80 \%$ successful trials.

Since groups of narrow-striped mongooses always forage together (Schneider and Kappeler 2016), other group members (observers) were present in the experimental arena and could approach the demonstrator while she manipulated the apparatus. To assess the propensity to seek social information, we placed a metal ring $(50 \mathrm{~cm}$ diameter, the same metal ring used during the novel object tests) around the feeding apparatus during the presentation, allowing us to measure the time spent close to the demonstrator for each observer. To prevent observers from manipulating the boxes during the training of demonstrators, the hinge of the door was built tight, so that it stayed open and did not close automatically after the demonstrator let the door loose. In addition, only one piece of cat food was placed in the box for the demonstrator, preventing observers from scrounging.

\section{Group testing procedure}

After the demonstrator had learned the task, we tested the entire group. We presented several boxes corresponding to the number of individuals in a group to avoid monopolisation of the apparatuses by the dominant female. The boxes were now baited with ten pieces of dry cat food to allow individuals to perform several trials repeatedly while both opening mechanisms were available. This time the door of the boxes closed automatically after the individual let the door loose, so that they had to open it again to obtain access to another reward. For the group testing procedure, each presentation of the apparatuses per group was considered as one session. Within a session, an individual could perform several trials. Subjects were tested until they reached a learning criterion of $80 \%$ of successful trials out of a minimum of 15 trials. Since several pieces of dry cat food were available, the apparatuses were not re-baited after each trial and were only removed after the last individual left the experimental arena.

\section{Video analyses}

During the experiments, subjects were video-taped with a camcorder (SONY HDR-CX 240), and videos were analysed using Boris (Friard and Gamba 2016). From the demonstrator training sessions, we assessed social learning opportunities, which were defined as the time an observer spent together with a demonstrator within the metal ring, while the demonstrator was actively manipulating the boxes. To measure individual learning performance, we scored individual learning speed during the demonstrator training sessions and the group testing sessions. Learning speed was defined as the number of trials needed by an individual to reach the learning criterion, which was $80 \%$ of successful trials.

\section{Statistical analyses}

We conducted all analyses using $\mathrm{R}$ statistical software ( $\mathrm{R}$ Core Team 2017). First, to examine whether social learning opportunities co-varied with neophobia, we conducted Spearman's correlation test between neophobia and social learning opportunities. Second, we examined whether the learning speed of observers in the demonstrator groups was predicted by neophobia and social learning opportunities by fitting a GLMM with a Poisson structure, using the package lme4 (Bates et al. 2014). Learning speed corresponds to the number of trials required by an individual to reach the learning criterion ( $80 \%$ of correct trials). Learning speed was fitted as the response variable and neophobia and social learning opportunities were fitted as fixed factors. We initially included the interaction term between fixed factors and we checked its significance using likelihood test ratio. When non-significant, the interaction between fixed factors was dropped from the analysis and the single terms were kept in the model. As the members of a group were present at the experimental arena during each test, we tested multiple individuals together at the same time. We, therefore, included group identity as random factor in the model.

Third, we examined whether learning speed was influenced by the presence of a demonstrator (yes or no). For this analysis, we used a Cox proportional hazards model with learning speed as the dependent variable, treating whether the individual learned the task or not (yes or no) as censored observations. The Cox model was conducted using the R-package "survival" (Therneau 2015).

Fourth, we examined whether observers in the pull and slide groups differed in the proportion of trials during which they used the pull technique using a Mann-Whitney $U$ test. We also performed exact binomial tests to examine whether individuals in both the demonstrator and control groups developed a preference for one technique to solve the twooption task. We defined a preference when individuals used one technique more often than expected by chance to solve 
the two-option task. Moreover, using binomial tests, we examined whether the number of individuals that developed a preference differed from those that did not develop a preference for all groups and in the demonstrator groups only.

For the mixed models, we checked for collinearity between the fixed factors prior to all analyses. For all models, we performed likelihood test ratio for the full-null model comparisons and we visually inspected normality and homoscedasticity with residual plots. For the Cox proportional hazards model, we checked for the violation of proportional hazards.

\section{Results}

\section{Neophobia}

The latency to feed next to the novel object was significantly repeatable over time $(R=0.439, p=0.04)$, whereas the latency to enter the ring $(R=0.001, p=0.149)$ and the latency to contact the novel object $(R=0.073, p=0.44)$ were not repeatable. Hence, we consider the latency to feed next to the novel object as neophobia. Neophobia did not correlate with social learning opportunities however (Spearman's rank correlation test: $r=0.009, p=0.989$ ).

\section{Use of social information for learning}

During the demonstrator training sessions, all five demonstrators learned to open the feeding apparatus. Four out of five demonstrators required 20 trials to learn the task, whereas one demonstrator (from group N) needed 28 trials. On average, the demonstrators needed $21.6 \pm 3.6$ $($ mean $\pm \mathrm{SD})$ trials to learn the task. Demonstrators needed on average $5.24 \mathrm{~s}$ (median, IQR: $4.77, N=3$ ) to open the door using the pull technique and $4.42 \mathrm{~s}$ (median, IQR: $5.27, N=2$ ) using the slide technique, suggesting that both techniques were equally difficult. During the group testing sessions, five out of seven observers in the pull groups and three out of four observers in the slide groups learned the task within $31 \pm 16($ mean $\pm S D)$ trials. In the control groups, four individuals participated, but only one individual learned the task after 55 trials.

The learning speed of observers co-varied with the presence of a demonstrator ( $p=0.037$, Table 2$)$, with individuals in demonstrator groups learning the task faster compared to individuals in control groups (Fig. 2). During the demonstrator training sessions, observers spent on average $6.7 \pm 13.7$ min (mean $\pm \mathrm{SD})$ within the metal ring together with the demonstrator, our measure of social learning opportunities. We found that learning speed was influenced by both neophobia ( $p=0.011$; Table $3 \mathrm{a})$ and social learning

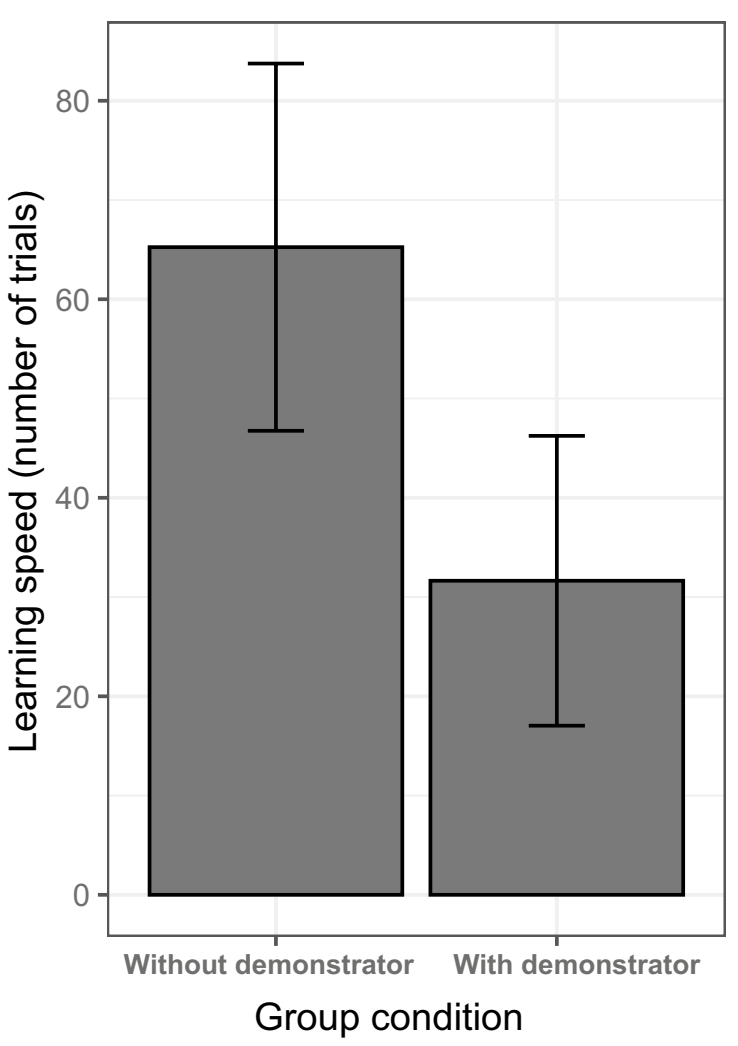

Fig. 2 Difference in learning speed between individuals provided with demonstrators (pull and slide groups) and individuals without demonstrators (control groups): individuals in groups with a demonstrator learned the task faster

Table 2 Result of the Cox's proportional hazards model assessing the effect of the presence of the demonstrator on individuals' learning performances $(N=15)$

\begin{tabular}{|c|c|c|c|c|c|c|c|}
\hline Model & Fixed effect & Censor variable & $B \pm \mathrm{SE}$ & $Z$ & e $(95 \% \mathrm{CI})$ & $P$ value & $\begin{array}{l}\text { Test for the proportional } \\
\text { hazards }\end{array}$ \\
\hline $\begin{array}{l}\text { Effect of the presence of } \\
\text { demonstrator on learning } \\
\text { speed }\end{array}$ & Learning speed & Learning (yes or no) & $2.32 \pm 1.11$ & 2.08 & $10.23(1.15 ; 90.8)$ & 0.0369 & 0.486 \\
\hline
\end{tabular}

$B$ beta coefficient; $S E$ standard error; $z$ Wald statistic value; $P$ p value; e: exponentially transformed parameter estimates show the proportional change of hazard ratio, that is, the probability of solving the task, in response to unit change of predictors.; $C I$ confidence interval of the hazard ratio Bold value indicates statistically significant result at the significance threshold $p<0.05$ 
opportunities $(p<0.001$; Table 3a), with less neophobic individuals and individuals seeking social learning opportunities for longer learning faster. Since one observer had a much longer latency to feed next to the novel object compared to the other individuals, we repeated the model without this outlier and obtained similar results for both neophobia ( $p=0.022$; Fig. 3 ; Table $3 b$ ) and social learning opportunities ( $p<0.001$; Fig. 4 ; Table 3b).

We also found that the proportion trials in which they used the pull technique differed between pull and slide groups, with observers in pull groups using the pull technique more often whereas observers in the slide groups used the pull technique less often and, hence, the slide technique more often (Mann Whitney $U$ test, $W=25, p=0.042$, Fig. 5). All demonstrators maintained the technique learned during the group testing sessions, although three out of five demonstrators also discovered the other technique (Table 4). Overall, independent of whether individuals reached the learning criterion or not, eight individuals developed a preference for one technique and six exhibited no preference (binomial test, $p=0.795$, Table 4). In the demonstrator groups, seven individuals developed a preference, whereas only one developed a preference in the control groups $(N=1$, one-tailed binomial test, $p=0.035)$. However, from the seven individuals that developed a preference, five preferred the demonstrated technique whereas two individuals exhibited a preference for the other technique (one-tailed binomial test, $p=0.227$ ).

\section{Discussion}

We investigated the effect of neophobia on social learning in wild narrow-striped mongooses. Neophobia did not correlate with the propensity to seek social information. Less neophobic individuals and those that spent more time with the demonstrators during the demonstrator's training sessions learned the task faster, suggesting that personality and social facilitation enhanced learning. The improvement of learning performance in the presence of a demonstrator indicates that local or stimulus enhancement may have fostered the acquisition of the different opening techniques. Moreover, the proportion of animals using the pull technique differed between observers in the pull and slide groups, indicating that individuals in the pull groups used the demonstrated technique more often, and five out of seven individuals developed a preference for the demonstrated technique. Hence, narrow-striped mongooses appear to rely on inadvertent social learning processes, such as social facilitation and local or stimulus enhancement, to deal with new challenges, such as the artificial feeding boxes.

In contrast to other species (Kurvers et al. 2010b), neophobia did not co-vary with the observers' propensity to seek social information during the training sessions. However, both, neophobia and the tendency to seek social information influenced learning speed. Less neophobic individuals learned faster, supporting the hypothesis that fast personality types learn faster than slow personality types in a new situation (Sih and Del Giudice 2012). Moreover, the tendency to seek social information varied across individuals, indicating an attendance bias, which has been recognised to indicate directed social learning or transmission bias (Kendal et al. 2015). Narrow-striped mongooses that were more likely to seek social information also learned the task faster. Since the demonstrator was the dominant female of each group, the attendance bias might result from social inhibition by dominant females, constraining some observer's tendency to approach her closely to avoid aggression (Schneider and Kappeler 2016).

Similarly, in meerkats and chimpanzees (Pan troglodytes), the rank of demonstrators influenced the tendency of lowerranking individuals to seek social information during social learning (meerkats: Thornton and Malapert 2009; chimpanzees: Watson et al. 2017). Moreover, in Amazonian parrots (Amazonia amazonica), individuals receiving aggression at an artificial feeding apparatus interacted less often with the apparatus, thereby constraining their social learning opportunities (Morales Picard et al. 2017). In chacma baboons (Papio ursinus), boldness/neophobia did not co-vary with the tendency to pay attention to a demonstrator in a social learning experiment (Carter et al. 2014). As in our study, less neophobic individuals had greater learning success, but the tendency to seek social information did not influence learning success in baboons. Since the social learning task was relatively easy to solve, chacma baboons probably did not need much social information to solve the task, which benefitted bolder individuals that were more likely to interact with the novel food or feeding apparatus in solving the task faster (Carter et al. 2014). Hence, personality, but also the use of social information, can influence learning strategies when individuals are confronted with a new challenge.

Similarly, as several other species, such as red-fronted lemurs (Eulemur rufifrons; Schnoell and Fichtel 2012), Amazonian parrots (Morales et al. 2017) or blue tits (Cyanistes caeruleus; Aplin et al. 2013), narrow-striped mongooses in demonstrator groups learned the task faster than those in groups without a demonstrator, suggesting that the presence of a knowledgeable individual may have facilitated learning via local or stimulus enhancement (Hoppit and Laland 2008).

Narrow-striped mongooses also discovered the alternative technique to open the box. Individuals belonging to the demonstrator groups performed the demonstrated technique more often than the other one. Our findings here echo results from previous studies in which observers tended to adopt the technique displayed by the demonstrators or knowledgeable individuals (meerkats: Thornton and Malapert 2009, banded 


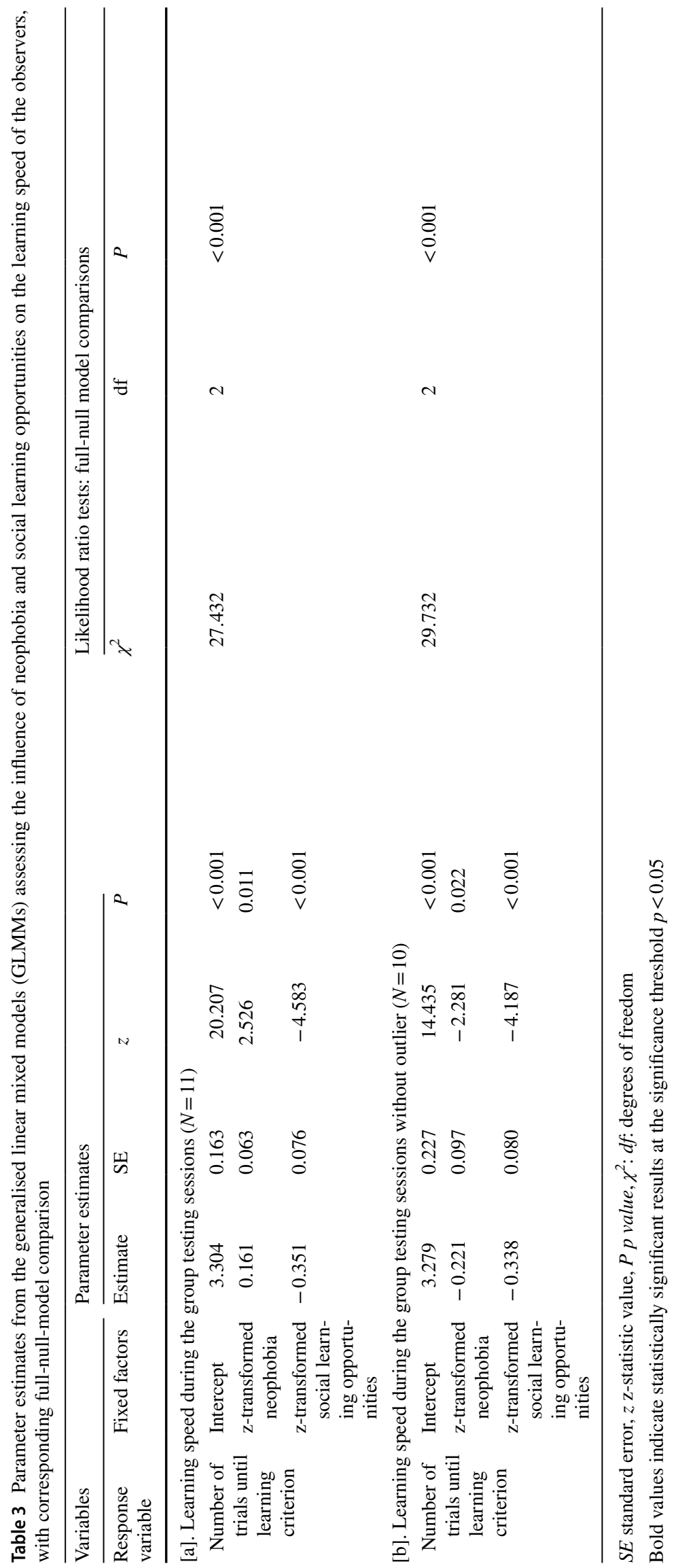




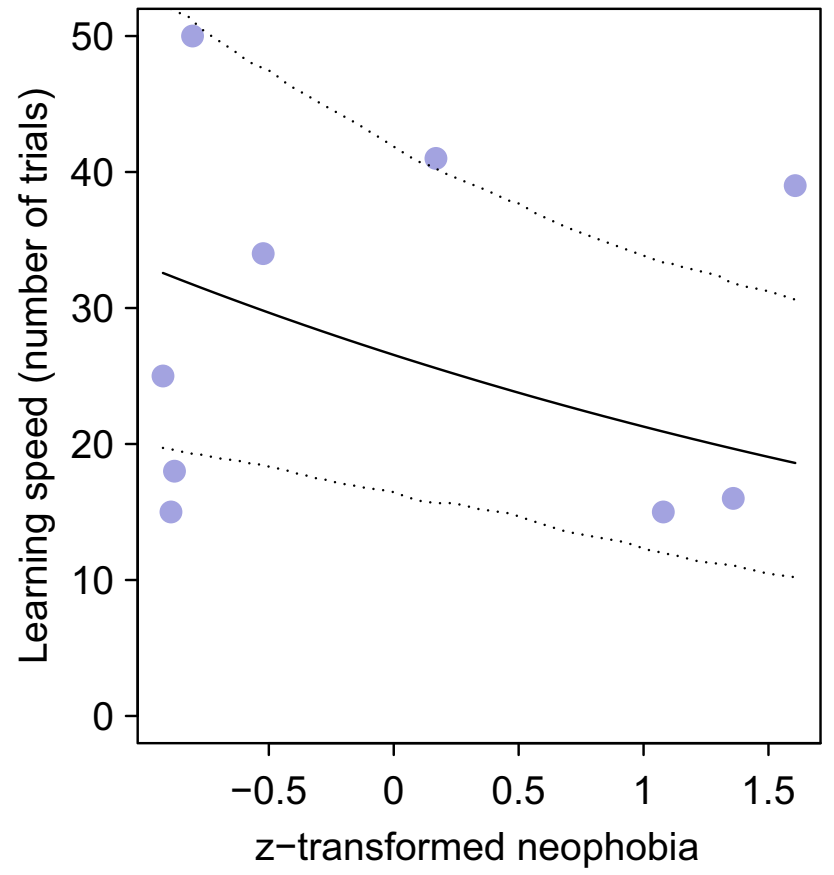

Fig.3 Influence of neophobia on individual learning speed during the testing sessions. Less neophobic individuals learned the task faster. The $\mathrm{X}$-axis depicts the latency to feed close to a novel object as proxy of neophobia, with negative values representing less neophobic individuals and positive values for the more neophobic ones. Each circle represents an individual that learned the discrimination learning task. The continuous line depicts the fitted model, and the dotted lines depict its bootstrapped $95 \%$ confidence intervals

mongooses: Müller and Cant 2010, red-fronted lemurs: Schnoell and Fichtel 2012, and vervet monkeys: van de Waal et al. 2013). However, in the pull groups, only 2 out of 4 individuals that developed a preference preferred the pull technique. In the slide groups, all individuals that developed a preference, preferred the demonstrated slide technique. Hence, despite the fact that observers in the demonstrator groups used the demonstrated technique more often, not all individuals developed a preference for the demonstrated technique.

To summarize, we found that neophobia but also social information influenced problem-solving abilities in narrow-striped mongooses. Less neophobic individuals and those that tended to seek social information learned the task faster and the presence of a demonstrator facilitated learning, indicating the use of inadvertent social learning strategies, such as social facilitation and local or stimulus enhancement, to solve problems. Hence, our results emphasize the importance of also considering personality traits to obtain a more comprehensive view of social learning strategies. Finally, similar to other mongooses (Thornton and Malapert 2009), narrow-striped mongooses rely on the use of social information to solve problems, informing

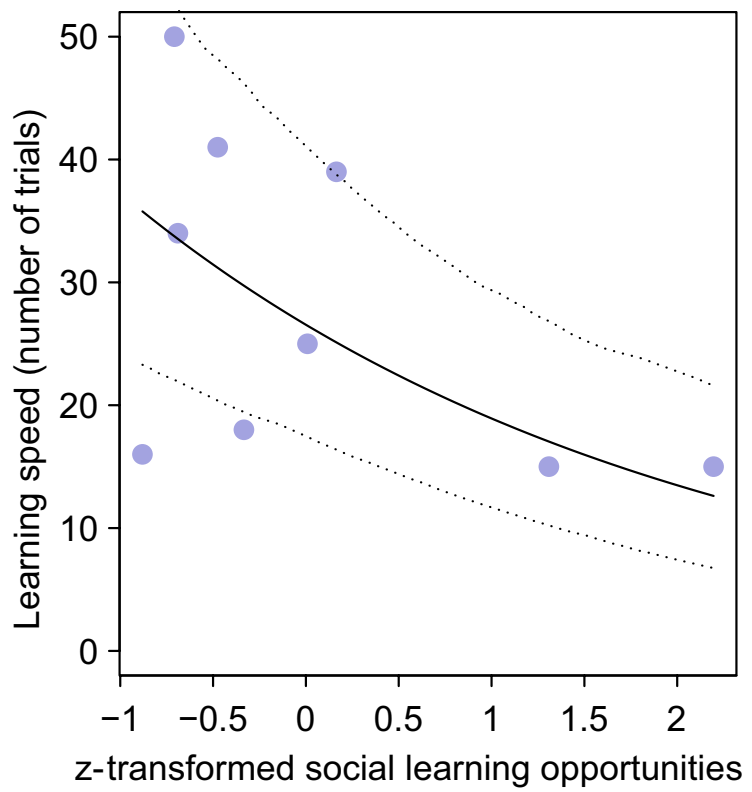

Fig. 4 Influence of the tendency to seek social information on learning speed. Individuals who spent more time with the demonstrators within the metal ring solved the task faster. Each circle represents an individual that learned the discrimination learning task. The continuous line depicts the fitted model, and the dotted lines depict its bootstrapped $95 \%$ confidence intervals

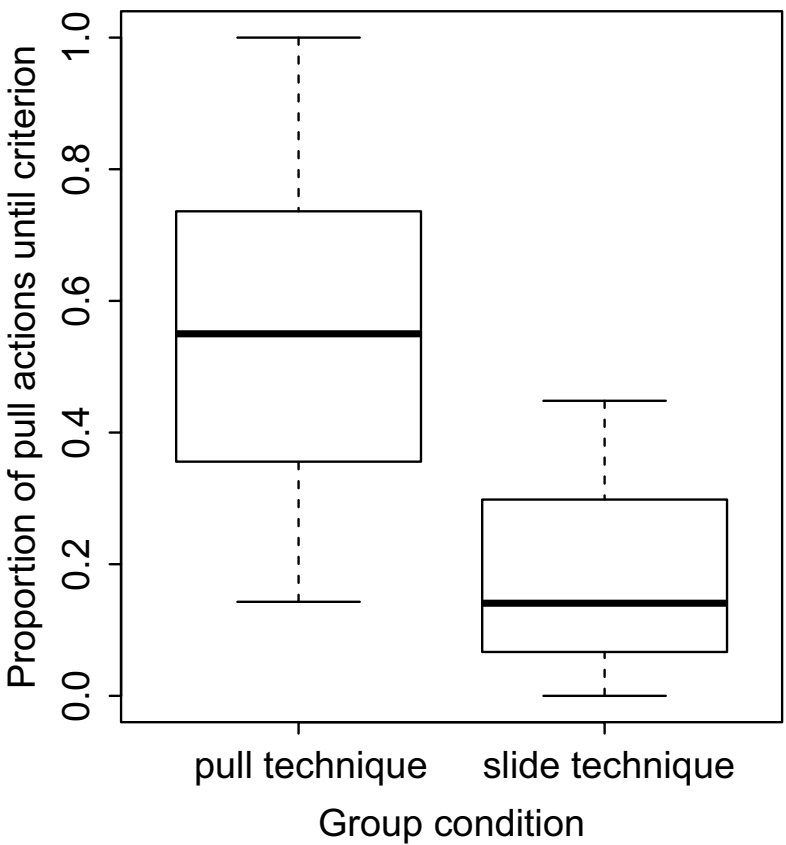

Fig. 5 Proportion of pull actions made by individuals in the pull and slide groups. Individuals in the pull condition performed the pull actions more often compared to individuals in the slide groups

our understanding of social learning among carnivorans with different social systems. 
Table 4 Results of the exact binomial tests to assess preferences for sliding or pulling techniques for each tested individual

\begin{tabular}{|c|c|c|c|c|c|c|}
\hline Group & ID & Role & Learner & $\begin{array}{l}\text { Pull actions } \\
\text { performed }\end{array}$ & $\begin{array}{l}\text { Slide actions } \\
\text { performed }\end{array}$ & $p$ value \\
\hline \multicolumn{7}{|c|}{ Groups assigned to the pull condition } \\
\hline \multirow[t]{2}{*}{ G1 } & 44 & Demonstrator & - & 14 & 1 & $<0.001$ \\
\hline & 97 & Observer & No & 8 & 1 & 0.03 \\
\hline \multirow[t]{5}{*}{$\mathrm{C}$} & 76 & Demonstrator & - & 13 & 0 & $<0.001$ \\
\hline & 15 & Observer & Yes & 11 & 33 & 0.001 \\
\hline & 22 & Observer & Yes & 22 & 18 & 0.635 \\
\hline & 86 & Observer & Yes & 7 & 5 & 0.774 \\
\hline & 87 & Observer & No & 4 & 24 & $<0.001$ \\
\hline \multirow[t]{3}{*}{$\mathrm{N}$} & 95 & Demonstrator & - & 14 & 0 & $<0.001$ \\
\hline & 94 & Observer & Yes & 6 & 7 & 1 \\
\hline & 99 & Observer & Yes & 20 & 0 & $<0.001$ \\
\hline \multicolumn{7}{|c|}{ Groups assigned to the slide condition } \\
\hline \multirow[t]{4}{*}{ M } & 40 & Demonstrator & - & 2 & 11 & 0.02 \\
\hline & 81 & Observer & Yes & 4 & 26 & $<0.001$ \\
\hline & 89 & Observer & Yes & 4 & 23 & $<0.001$ \\
\hline & 90 & Observer & Yes & 0 & 12 & $<0.001$ \\
\hline \multirow[t]{2}{*}{ L1 } & 75 & Demonstrator & - & 2 & 18 & $<0.001$ \\
\hline & 96 & Observer & No & 13 & 16 & 0.711 \\
\hline \multicolumn{7}{|c|}{ Groups assigned to the control condition } \\
\hline \multirow[t]{3}{*}{ B } & 13 & - & No & 11 & 21 & 0.11 \\
\hline & 66 & - & Yes & 18 & 26 & 0.291 \\
\hline & 88 & - & No & 19 & 46 & 0.001 \\
\hline $\mathrm{L}$ & 77 & - & No & 16 & 17 & 1 \\
\hline
\end{tabular}

Bold values indicate statistically significant results at the significance threshold $p<0.5$
Acknowledgements We would like to thank Léonard Razafimanantsoa and Rodin Rasoloarison for administrative and logistic support, Remy d'Ampataka for his help during fieldwork and the staff of the Kirindy Forest research station for their support. We appreciate the collaboration with the Département de Biologie Animale of the University of Antananarivo, the Ministère de $1^{\prime}$ Environnement, de $1^{\prime}$ Ecologie, de la Mer et des Forêts and the CNFEREF Morondava for authorizing our research in Kirindy. We are grateful to Debbie Kelly and four anonymous reviewers for their insightful comments on the earlier versions of this manuscript.

Author contributions B.N.R and C.F. designed the study. B.N.R conducted the experiments and conducted the videos analyses. B.N.R. and C.F. analysed the data. B.N.R., P.M.K. and C.F. wrote the paper. All authors read and approved the final manuscript.

Funding Open Access funding enabled and organized by Projekt DEAL. This study was funded by the "DAAD: Deutscher Akademischer Austauschdienst" (funding program/-ID: 57129429).

\section{Compliance with ethical standards}

Conflict of interest The authors declare that they have no conflict of interest.
Ethical approval All procedures performed in this study were in accordance with the ethical standards of the Ministère de 1'Environnement, de 1`Ecologie, de la Mer et des Forêts.

Electronic supplementary material supplementary material is available online at https://doi.org/10.6084/m9.figshare.12482021.

Open Access This article is licensed under a Creative Commons Attribution 4.0 International License, which permits use, sharing, adaptation, distribution and reproduction in any medium or format, as long as you give appropriate credit to the original author(s) and the source, provide a link to the Creative Commons licence, and indicate if changes were made. The images or other third party material in this article are included in the article's Creative Commons licence, unless indicated otherwise in a credit line to the material. If material is not included in the article's Creative Commons licence and your intended use is not permitted by statutory regulation or exceeds the permitted use, you will need to obtain permission directly from the copyright holder. To view a copy of this licence, visit http://creativecommons.org/licenses/by/4.0/.

\section{References}

Aplin L (2016) Understanding the multiple factors governing social learning and the diffusion of innovations. Curr Opin Behav Sci 12:59-65. https://doi.org/10.1016/j.cobeha.2016.09.003 
Aplin L, Sheldon BC, Morand-Ferron J (2013) Milk bottles revisited: social learning and individual variation in the blue tit, Cyanistes caeruleus. Anim Behav 85:1225-1232. https://doi.org/10.1016/j. anbehav.2013.03.009

Bates D, Mächler M, Bolker B, Walker S (2014) Fitting linear mixedeffects models using lme4. ArXiv Prepr ArXiv 14:65823

Benson-Amram S, Heinen VK, Gessner A et al (2014) Limited social learning of a novel technical problem by spotted hyenas. Behav Processes 109:111-120. https://doi.org/10.1016/j.bepro c.2014.09.019

Carter AJ, Marshall HH, Heinsohn R, Cowlishaw G (2014) Personality predicts the propensity for social learning in a wild primate. PeerJ 2:e283. https://doi.org/10.7717/peerj.283

Claidière N, Messer EJ, Hoppitt W, Whiten A (2013) Diffusion dynamics of socially learned foraging techniques in squirrel monkeys. Curr Biol 23(13):1251-1255

Crane AL, Ferrari MCO (2017) Patterns of predator neophobia: a meta-analytic review. Proc R Soc B Biol Sci 284:20170583. https://doi.org/10.1098/rspb.2017.0583

Crane AL, Mathiron AGE, Ferrari MCO (2015) Social learning in a high-risk environment: incomplete disregard for the 'minnow that cried pike' results in culturally transmitted neophobia. Proc R Soc B Biol Sci 282:20150934. https://doi.org/10.1098/ rspb.2015.0934

Friard O, Gamba M (2016) BORIS: a free, versatile open-source event-logging software for video/audio coding and live observations. Methods Ecol Evol 7:1325-1330. https://doi. org/10.1111/2041-210X.12584

Greggor AL, Thornton A, Clayton NS (2015) Neophobia is not only avoidance: improving neophobia tests by combining cognition and ecology. Curr Opin Behav Sci 6:82-89. https://doi.org/10.1016/j. cobeha.2015.10.007

Grüter C, Leadbeater E (2014) Insights from insects about adaptive social information use. Trends Ecol Evol 29:177-184. https://doi. org/10.1016/j.tree.2014.01.004

Heyes CM (1994) Social learning in animals: categories and mechanisms. Biol Rev 69:207-231

Holekamp KE, Sakai ST, Lundrigan BL (2007) Social intelligence in the spotted hyena (Crocuta crocuta). Philos Trans R Soc B Biol Sci 362:523-538. https://doi.org/10.1098/rstb.2006.1993

Hoppitt W, Laland KN (2008) Social processes influencing learning in animals: a review of the evidence. Adv Stud Behav 38:105-165

Kendal RL, Boogert NJ, Rendell L et al (2018) Social learning strategies: bridge-building between fields. Trends Cogn Sci 22:651665. https://doi.org/10.1016/j.tics.2018.04.003

Kendal R, Hopper LM, Whiten A et al (2015) Chimpanzees copy dominant and knowledgeable individuals: implications for cultural diversity. Evol Hum Behav 36:65-72. https://doi.org/10.1016/j. evolhumbehav.2014.09.002

Kendal RL, Galef BG, Van Schaik CP (2010) Social learning research outside the laboratory: how and why? Learn Behav 38:187-194. https://doi.org/10.3758/LB.38.3.187

Kurvers RHJM, Prins HHT, van Wieren SE et al (2010a) The effect of personality on social foraging: shy barnacle geese scrounge more. Proc R Soc B Biol Sci 277:601-608. https://doi.org/10.1098/ rspb.2009.1474

Kurvers RHJM, Van Oers K, Nolet BA et al (2010b) Personality predicts the use of social information: personality and social information use. Ecol Lett 13:829-837. https://doi.org/10.111 1/j.1461-0248.2010.01473.x

Laland KN (2004) Social learning strategies. Learn Behav 32:4-14

Marchetti C, Drent PJ (2000) Individual differences in the use of social information in foraging by captive great tits. Anim Behav 60:131140. https://doi.org/10.1006/anbe.2000.1443
Mesoudi A, Chang L, Dall SRX, Thornton A (2016) The evolution of individual and cultural variation in social learning. Trends Ecol Evol 31:215-225. https://doi.org/10.1016/j.tree.2015.12.012

Morales Picard A, Hogan L, Lambert ML et al (2017) Diffusion of novel foraging behaviour in Amazon parrots through social learning. Anim Cogn 20:285-298. https://doi.org/10.1007/s1007 1-016-1049-3

Müller CA, Cant MA (2010) Imitation and traditions in wild Banded Mongooses. Curr Biol 20:1171-1175. https://doi.org/10.1016/j. cub.2010.04.037

Nakagawa S, Schielzeth H (2010) Repeatability for Gaussian and nonGaussian data: a practical guide for biologists. Biol Rev no-no. https://doi.org/10.1111/j.1469-185X.2010.00141.X

Nomakuchi S, Park PJ, Bell MA (2009) Correlation between exploration activity and use of social information in three-spined sticklebacks. Behav Ecol 20:340-345. https://doi.org/10.1093/behec o/arp001

Pesendorfer MB, Gunhold T, Schiel A et al (2009) The maintenance of traditions in marmosets: individual habit, not social conformity? A field experiment. PLoS ONE 4:e4472. https://doi.org/10.1371/ journal.pone.0004472

R Core Team (2017) R: A language and environment for statistical computing. R Foundation for Statistical Computing, Vienna, Austria

Rasolofoniaina B, Razafy P, Razafimahatratra E, Kappeler PM (2019) Feeding ecology of the bokiboky, Mungotictis decemlineata (family Eupleridae). Malagasy Nature 13:152-161

Réale D, Reader SM, Sol D et al (2007) Integrating animal temperament within ecology and evolution. Biol Rev 82:291-318. https ://doi.org/10.1111/j.1469-185X.2007.00010.x

Rieucau G, Giraldeau L-A (2011) Exploring the costs and benefits of social information use: an appraisal of current experimental evidence. Philos Trans R Soc B Biol Sci 366:949-957. https:// doi.org/10.1098/rstb.2010.0325

Rosa P, Nguyen V, Dubois F (2012) Individual differences in sampling behaviour predict social information use in zebra finches. Behav Ecol Sociobiol 66:1259-1265. https://doi.org/10.1007/s0026 5-012-1379-3

Schneider TC, Kappeler PM (2016) Gregarious sexual segregation: the unusual social organization of the Malagasy narrow-striped mongoose (Mungotictis decemlineata). Behav Ecol Sociobiol 70:913-926. https://doi.org/10.1007/s00265-016-2113-3

Schnoell AV, Fichtel C (2012) Wild redfronted lemurs (Eulemur rufifrons) use social information to learn new foraging techniques. Anim Cogn 15:505-516. https://doi.org/10.1007/s1007 1-012-0477-y

Sih A, Del Giudice M (2012) Linking behavioural syndromes and cognition: a behavioural ecology perspective. Philos Trans R Soc B Biol Sci 367:2762-2772. https://doi.org/10.1098/rstb.2012.0216

Slaa EJ, Wassenberg J, Biesmeijer JC (2003) The use of field-based social information in eusocial foragers: local enhancement among nestmates and heterospecifics in stingless bees. Ecol Entomol 28:369-379. https://doi.org/10.1046/j.1365-2311.2003.00512.x

Therneau T (2015) A package for survival analysis in S. Version 2.38. https://CRAN.R-project.org/package=survival. Accessed 06 Nov 2019

Thornton A, Clutton-Brock T (2011) Social learning and the development of individual and group behaviour in mammal societies. Philos Trans R Soc B Biol Sci 366:978-987. https://doi. org/10.1098/rstb.2010.0312

Thornton A, Malapert A (2009) Experimental evidence for social transmission of food acquisition techniques in wild meerkats. Anim Behav 78:255-264. https://doi.org/10.1016/j.anbehav.2009.04.021

Thornton A, McAuliffe K (2006) Teaching in Wild Meerkats. Science 313:227-229. https://doi.org/10.1126/science.1128727 
van de Waal E, Bshary R (2011) Social-learning abilities of wild vervet monkeys in a two-step task artificial fruit experiment. Anim Behav 81:433-438

van de Waal E, Claidière N, Whiten A (2013) Social learning and spread of alternative means of opening an artificial fruit in four groups of vervet monkeys. Anim Behav 85:71-76. https://doi. org/10.1016/j.anbehav.2012.10.008

van de Waal E, Renevey N, Favre CM, Bshary R (2010) Selective attention to philopatric models causes directed social learning in wild vervet monkeys. Proc R Soc B 277:2105-2111. https://doi. org/10.1098/rspb.2009.2260

Watson SK, Reamer LA, Mareno MC et al (2017) Socially transmitted diffusion of a novel behavior from subordinate chimpanzees. Am J Primatol 79:e22642. https://doi.org/10.1002/ajp.22642

Watson SK, Vale GL, Hopper LM et al (2018) Chimpanzees demonstrate individual differences in social information use. Anim Cogn 21:639-650. https://doi.org/10.1007/s10071-018-1198-7

Webster MM, Laland KN (2017) Social information use and social learning in non-grouping fishes. Behav Ecol 28:1547-1552. https ://doi.org/10.1093/beheco/arx121
Webster SJ, Lefebvre L (2001) Problem solving and neophobia in a columbiform-passeriform assemblage in Barbados. Anim Behav 62:23-32. https://doi.org/10.1006/anbe.2000.1725

Whiten A, Mesoudi A (2008) Establishing an experimental science of culture: animal social diffusion experiments. Philos Trans R Soc B Biol Sci 363:3477-3488. https://doi.org/10.1098/rstb.2008.0134

Whiten A, van de Waal E (2018) The pervasive role of social learning in primate lifetime development. Behav Ecol Sociobiol. https:// doi.org/10.1007/s00265-018-2489-3

Publisher's Note Springer Nature remains neutral with regard to jurisdictional claims in published maps and institutional affiliations. 